\title{
Knowledge, Attitudes and Practices of Sudanese Women Regarding the Pap Smear Test and Cervical Cancer
}

\author{
Ahmed O Almobarak ${ }^{1}$, Ayman A Elbadawi ${ }^{2}$, Wadie M Elmadhoun ${ }^{3}$, Mohammed \\ H Elhoweris ${ }^{4}$, Mohammed H Ahmed ${ }^{5 *}$
}

\begin{abstract}
Background: Despite the established role of the Pap smear test (PST) in prevention and early detection of cervical cancer, it is still rarely practiced in Sudan. Many challenges hinder the establishment of an effective cervical cancer screening program, including socio-cultural factors. Therefore, this study aimed to investigate the knowledge, attitudes and practices (KAP) of Sudanese women with regard to the Pap smear test and cervical cancer. Materials and Methods: A total of 500 married women aged 14 to 58 years were recruited from obstetric clinics, hospitals and universities in Khartoum in 2014. Data were collected using a standardized, pretested questionnaire that inquired socio-demographic characteristics and their KAP about cervical cancer and the PST. Results: More than $52 \%$ of participating women were above 30 years of age, and the majority (78.8\%) were university degree holders. A total of $486(97.2 \%)$ of participants were resident in urban areas of Khartoum State. However about $48 \%$ of the respondents had never heard about PST, and only $15.8 \%$ of the participants had undergone a Pap smear test previously; 46.6\% (233/500) knew that the human papilloma virus (HPV) was the causative agent, but only 39.2\% (196/500) had heard about HPV vaccination, and only 11.4\% (57/500) had received the vaccine. However $68 \%$ of the respondents agreed to do Pap smear if properly informed about the test and $75.4 \%$ of the respondents agreed to participate in a cervical cancer screening program. Conclusions: Despite a high educational level, less than half of our participants had accurate knowledge about cervical cancer, HPV, and cervical cancer screening. Health education about cervical cancer, HPV and sexually transmitted infections and the role of PST in cervical cancer prevention are crucial when designing interventions aimed at improving cervical cancer screening for Sudanese women.
\end{abstract}

Keywords: Pap smear - cervical cancer - HPV - vaccination - knowledge - Sudan

Asian Pac J Cancer Prev, 17 (2), 625-630

\section{Introduction}

Cervical cancer is the second most common cancer among women worldwide, with approximately 500,000 new cases and 274,000 deaths annually. About $88 \%$ of the cases are in developing countries, accounting for $13 \%$ of all female cancers (WHO report, 2008).

Human papillomavirus (HPV) infection is associated with virtually all cases of cervical cancer (Al Zaabi et al., 2015). Long term infection with high-risk strains of HPV can lead to the development of cervical dysplasia and cancer (Khan et al., 2005).

The introduction of the conventional Papanicolaou (Pap) smear test in the developed countries has led to a dramatic decrease in mortality of cervical cancer (Saslow et al., 2002).Cervical cancer ranked second after breast cancer among Sudanese women, and current published estimates from National Health Laboratory in Sudan indicate that every year about 833 Sudanese women are diagnosed with cervical cancer (estimated age standardized incidence: 7.9 per 100,000 per year, in addition, about 534 die from the disease (Elamin et al., 2015).

In Sudan, like other developing countries, the coverage of screening programs is still incomplete due to lack of infrastructures and trained healthcare professionals, poor health care access, and lack of awareness. The majority of women who underwent Pap test were tested on an opportunistic occasion. Published data showed that only about $5 \%$ of women in developing countries have been screened for cervical dysplasia, compared with $40 \%$ to $50 \%$ of women in developed countries (WHO report, 1986).Cervical cancer is a preventable disease and starts with pre-cancerous early stages that can be treated. In addition, the invasive stages of the disease

${ }^{1}$ Department of Pathology, Faculty of Medicine, University of Medical Sciences and Technology, ${ }^{2}$ Faculty of Medical Laboratory Sciences, Elnileen University, Khartoum, ${ }^{3}$ Department of Pathology, Faculty of Medicine and Health Sciences, Nile Valley University, Atbara, Sudan, ${ }^{4}$ Histopathology and Cytology Department, SRL Diagnostics, Dubai Healthcare City, Dubai, UAE, ${ }^{5}$ Department of Medicine, Milton Keynes University Hospital NHS Foundation Trust, Eaglestone, Milton Keynes, Buckinghamshire, UK *For correspondence:elziber@yahoo.com 
Ahmed O Almobarak et al

require appropriate surgery and radiotherapy which are unavailable in most developing countries.

The most common challenges in cervical cancer prevention programs in developing countries are, increasing women's awareness, increasing provider knowledge and skills, and effective monitoring and evaluation approaches (Wellensiek et al., 2002; Gichang et al., 2003). Generally, reports from many developing countries indicated that women had inadequate knowledge of causes, risks and prevention of cervical cancer (Maaita and Barakat, 2002).

The aim of this study was to investigate knowledge, attitudes and practicesof Sudanese women about Pap smear, HPV, and Cervical cancer and to evaluate the barriers to cervical cancer screening in Sudan.

\section{Materials and Methods}

\section{Study design and setting}

This cross-sectional, population-based study was conducted to investigate women's knowledge, attitudes, and practices regarding Pap smear, HPV and cervical cancer screening. The research protocol was approved by the ethics committee of Elnileen University; and all participants gave written informed consent.

\section{Participants}

Table 1. Sociodemographic Characteristic of Study Population $(\mathbf{n}=500)$

\begin{tabular}{|c|c|}
\hline Characteristic & $\mathrm{n}(\%)$ \\
\hline \multicolumn{2}{|l|}{ Category of profession } \\
\hline Medical & $300(60.0)$ \\
\hline Non-medical & $200(40.0)$ \\
\hline \multicolumn{2}{|l|}{ Age group (years) } \\
\hline Below 15 & $(0.4)$ \\
\hline $16-20$ & $(1.8)$ \\
\hline $21-25$ & $93 \quad(18.6)$ \\
\hline $26-30$ & $134(26.8)$ \\
\hline Above 30 & $262(52.4)$ \\
\hline \multicolumn{2}{|l|}{ Religion } \\
\hline Muslim & $479(95.8)$ \\
\hline Christian & $21 \quad(4.2)$ \\
\hline \multicolumn{2}{|l|}{ Residence } \\
\hline Khartoum state & $473(94.6)$ \\
\hline Urban outside Khartoum & $13 \quad(2.6)$ \\
\hline Rural area & $14 \quad(2.8)$ \\
\hline \multicolumn{2}{|l|}{ Educational level } \\
\hline Illiterate & $12 \quad(2.4)$ \\
\hline Primary & $32 \quad(6.4)$ \\
\hline Secondary & $62 \quad(12.4)$ \\
\hline University & $282(56.4)$ \\
\hline postgraduate & $112(22.4)$ \\
\hline \multicolumn{2}{|l|}{ Husband educational level } \\
\hline Illiterate & $(2.0)$ \\
\hline Primary & $18 \quad(3.6)$ \\
\hline Secondary & $65 \quad(13.0)$ \\
\hline University & $341(68.2)$ \\
\hline postgraduate & $66 \quad(13.2)$ \\
\hline \multicolumn{2}{|l|}{ Health insurance coverage } \\
\hline Yes & $290(58.0)$ \\
\hline No & $210(42.0)$ \\
\hline
\end{tabular}

Participants were 500 women aged between 14-58 years old that were recruited from obstetric clinics, governmental and private hospitals, and universities in Khartoum, Sudan in 2014. There were 300 participants from the medical field while 200 were non-medicals.

\section{Measures and data collection}

The designed questionnaire was a self-administered that addressed demographic data about participants and their husbands and questions about knowledge of, altitude toward, and practices of Pap smear test, cervical cancer, HPV, HPV vaccine and cervical cancer screening.

\section{Analysis}

Frequency distributions were used to present the characteristics of the studied women population. Cross tabulations were conducted to test for the hypothesized effects of demographic data on the knowledge of, attitude

Table 2. Marital, obstetric and gynecologic history of study population. $(n=500)$

\begin{tabular}{|c|c|c|}
\hline \multirow{2}{*}{$\frac{\text { Characteristic }}{\text { Age at marriage (year }}$} & \multicolumn{2}{|c|}{$\mathrm{n}(\%)$} \\
\hline & & \\
\hline Below 15 & 76 & $(15.2)$ \\
\hline $16-20$ & 68 & $(13.5)$ \\
\hline $21-25$ & 183 & $(36.6)$ \\
\hline $26-30$ & 104 & $(20.6)$ \\
\hline Above 30 & 69 & $(13.8)$ \\
\hline \multicolumn{3}{|c|}{ Total duration of marriage(years) } \\
\hline 1-May & 235 & $(47.0)$ \\
\hline 6-Oct & 86 & $(17.2)$ \\
\hline Nov-15 & 61 & $(12.2)$ \\
\hline $16-20$ & 72 & $(14.4)$ \\
\hline More than 20 & 46 & $(9.2)$ \\
\hline \multicolumn{3}{|c|}{ History of regular contraceptive usage } \\
\hline Yes & 275 & $(55.0)$ \\
\hline No & 225 & $(45.0)$ \\
\hline \multicolumn{3}{|c|}{ History of circumcision } \\
\hline Yes & 409 & $(81.8)$ \\
\hline No & 91 & $(18.2)$ \\
\hline \multicolumn{3}{|c|}{ Number of pregnancies } \\
\hline Nil & 98 & (19.6) \\
\hline One & 89 & $(17.8)$ \\
\hline Two & 75 & $(15.0)$ \\
\hline Three & 42 & $(8.4)$ \\
\hline Four & 136 & $(27.2)$ \\
\hline More than 4 & 60 & $(12.0)$ \\
\hline \multicolumn{3}{|l|}{ Number of child birth } \\
\hline Nil & 76 & $(15.2)$ \\
\hline Once & 76 & $(15.2)$ \\
\hline Twice & 76 & $(15.2)$ \\
\hline Three times & 76 & $(15.2)$ \\
\hline Four or more & 76 & $(15.2)$ \\
\hline \multicolumn{3}{|l|}{ Number of stillbirth } \\
\hline Nil & 225 & $(45.0)$ \\
\hline One & 75 & $(15.0)$ \\
\hline Two & 52 & $(10.4)$ \\
\hline Three & 64 & $(12.8)$ \\
\hline Four & 58 & (11.6) \\
\hline More than four & 26 & $(5.2)$ \\
\hline \multicolumn{3}{|c|}{ History of having a full gynecological examination } \\
\hline Yes & 184 & $(36.8)$ \\
\hline No & 316 & $(63.2)$ \\
\hline
\end{tabular}


Table 3. Knowledge, attitudes and Practices of Married Sudanese Women about Pap Smear, HPV and Cervical Cancer $(\mathbf{n}=\mathbf{5 0 0})$

\begin{tabular}{lc}
\hline Characteristic & $\mathrm{n}(\%)$ \\
\hline Ever heard about Pap smear (cervical sample) & \\
yes & $258(51.6)$ \\
no & $242(48.4)$ \\
Source of knowledge about Pap smear & \\
$\quad$ Family/friends & $36(14.0)$ \\
General Practitioner & $37(14.3)$ \\
My gynecological doctor & $53(20.5)$ \\
Nurse & $29(11.2)$ \\
Media & $103(40)$ \\
Ever had a Pap smear & $79(15.8)$ \\
yes & $421(84.2)$ \\
no & \\
Ever heard about cervical cancer & $439(87.8)$ \\
yes & $61(12.2)$ \\
no &
\end{tabular}

Knowledge about risk factors for cervical cancer

Early age at marriage

$\begin{array}{lr}\text { Yes } & 55(11.0) \\ \text { No } & 445(89.0)\end{array}$

Early age at first pregnancy

Yes

No

$7(1.4)$

493 (98.6)

Multiple partners

Yes

$35(7.0)$

No

$465(93)$

High risk male partner

Yes

$23(4.6)$

No

$477(95.4)$

Smoking

Yes

No

$51(10.2)$

$449(89.8)$

$66(13.2)$

$434(86.8)$

Sexually Transmitted infections Yes

$7(1.4)$

No

493 (98.6)

Too frequent childbirth

Yes $15 \quad 13.0$

No $\quad 485(97.0)$

Poor personal hygiene

Yes $67(13.4)$

No 437 (86.7)

Low socio-economic status

Yes $\quad 5(1.0)$

No $\quad 495$ (99.0)

Genital infection by HPV, HIV or Chlamydia

$\begin{array}{ll}\text { Yes } & 212(42.4) \\ \text { No } & 288(57.6)\end{array}$

Ever heard that HPV is the causative agent of cervical cancer

$\begin{array}{ll}\text { Yes } & 233(46.6) \\ \text { No } & 267(53.4)\end{array}$

Know whether cervical cancer is preventable

$\begin{array}{ll}\text { Yes } & 328(65.6) \\ \text { No } & 172(34.4)\end{array}$

Know whether Pap smear can identify early asymptomatic lesions

$\begin{array}{ll}\text { Yes } & 277(55.4) \\ \text { No } & 223(44.6)\end{array}$

Know early detection of cervical cancer has good effect on outcome of treatment
Yes
$388(77.6)$
No
$112(22.4)$

Table 3. Knowledge, Attitudes and Practices of Married Sudanese Women about Pap Smear, HPV and Cervical Cancer $(\mathbf{n = 5 0 0 )}$ (Continue)

\begin{tabular}{|c|c|}
\hline Characteristic & $\mathrm{n}(\%)$ \\
\hline \multicolumn{2}{|l|}{ Ever heard about a vaccine for HPV } \\
\hline Yes & $196(39.2)$ \\
\hline No & $304(60.8)$ \\
\hline \multicolumn{2}{|l|}{ Ever have had HPV vaccine } \\
\hline Yes & $57(11.4)$ \\
\hline No & $443(88.6)$ \\
\hline \multicolumn{2}{|c|}{ If properly informed about Pap smear, would you do it? } \\
\hline Yes & $340(68.0)$ \\
\hline No & $160(32.0)$ \\
\hline \multicolumn{2}{|c|}{ If refuse to do Pap smear, what are the causes? } \\
\hline May be painful & 39 (7.8)24.4\% \\
\hline I feel shy & 8 (1.6)5.0\% \\
\hline I am healthy, no need & $58(11.6) 36.3$ \\
\hline Husband would not agree & $16 \quad(3.2) 10 \%$ \\
\hline I don't care & $19 \quad(3.8) 11.9$ \\
\hline Physician doesn't request & $17 \quad(3.4) 10.6 \%$ \\
\hline Inaccessibility & $3(0.6) 1.9 \%$ \\
\hline \multicolumn{2}{|c|}{ If agree to do Pap smear, where is the preferable place? } \\
\hline Women clinic in hospital & $121(35.6)$ \\
\hline Private clinic & $90(26.5)$ \\
\hline Obs.\&Gyne clinic in hospital & $129(37.9)$ \\
\hline \multicolumn{2}{|c|}{ If agree to do Pap smear, whom do you prefer to perform it? } \\
\hline Family physician/GP & $1(0.3)$ \\
\hline Gynecologic doctor & $142(41.8)$ \\
\hline Maternal and child health doctor & $90(26.5)$ \\
\hline Private doctor & $89(26.2)$ \\
\hline Nurse & $18 \quad(5.3)$ \\
\hline \multicolumn{2}{|c|}{ Whether agree to participate in screening program? } \\
\hline Yes & $377(75.4)$ \\
\hline No & $123(24.6)$ \\
\hline
\end{tabular}

towards and practice of Papanicolaou test screening. The Pearson x coefficient was calculated and the significance level was set at p-value 0.05 and below.Statistical evaluation was done using the Statistical Package for Social Sciences (SPSS version 17.0).

\section{Results}

A total of 500 married Sudanese women participated in the study, $97.2 \%(486 / 500)$ lived in urban areas of Khartoum state, and $95.8 \%$ (479/500) were Muslims. The age range was between $14-58$ years; however, themajority belongs to the age group above 30 years (52.4\%). Moreover, 58\% (290/500) had medical insurance.

Regarding the education level only $2.4 \%$ (12/500) were illiterates, while $78.8 \%$ (394/500) were university graduates and above. Other Socio-demographic characteristics of participant were shown in Table 1 .

The marital, obstetric and gynecologic history of study participants were displayed in Table 2.

This survey showed that $51.8 \%$ (258/500) heard about Pap smear test but only $15.8 \%$ (79/500) had a Pap test before. Regarding the source of information aboutpap smear; the media (newspaper, television and internet) ranked first 40\% (103/258), Table 3.

Knowledge about cervical cancer and its risk factors were also studied, $87.8 \%$ (439/500) heard about cervical 
Table 4. Relationship between occupation and knowledge, attitude and practice of Pap smear. (n=500)

\begin{tabular}{|c|c|c|c|}
\hline Variable & Medical (n)\% & Non-medical(n)\% & $P$ value \\
\hline \multicolumn{4}{|l|}{ Ever heard about Pap smear } \\
\hline Yes & $220(73.3)$ & $38(19.0)$ & 0 \\
\hline No & $80(22.7)$ & $162(81.0)$ & \\
\hline \multicolumn{4}{|l|}{ Have had a Pap smear before } \\
\hline Yes & $68(30.9)$ & $11(5.5)$ & 0.48 \\
\hline No & $152(69.1)$ & $189(94.5)$ & \\
\hline \multicolumn{4}{|c|}{ Willingness to participate in a screening program } \\
\hline Yes & $260(86.7)$ & $117(58.5)$ & 0 \\
\hline No & $40(13.3)$ & $83(41.5)$ & \\
\hline \multicolumn{4}{|l|}{ Who do you prefer to perform the Pap smear } \\
\hline Family physician/GP & $0(0.0)$ & $1(0.9)$ & 0 \\
\hline Gyne. doctor & $93(40.3)$ & $49(45.0)$ & \\
\hline Maternal and child health doctor & $84(36.4)$ & $6(5.5)$ & \\
\hline Private doctor & $46(19.9)$ & $43(39.4)$ & \\
\hline Nurse & $8(3.5)$ & $10(9.2)$ & \\
\hline
\end{tabular}

cancer, $46.6 \%(233 / 500)$ heard about HPV as a causative agent and 39.2\% (196/500) heard about HPV vaccine, while only $11.4 \%(57 / 500)$ had the vaccine.

If properly informed, $68 \%$ (340/500) of studied women replied that they would have Pap test and 75.4\% (377/500) agreed to participate in screening program if available. Genital infection by HPV, HIV or Chlamydia ranked first $42.4 \%(212 / 500)$ as known risk factor, followed by poor personal hygiene $(13.4 \%)$ by the studied population .

The major barriers against having pap smear were as follows: $36.2 \%$ (58/160) of studied women thought that they were healthy so no need to have the test, and $24.3 \%$ (39/160) thought that it might be painful, and only10\% $(16 / 160)$ thought that their husband may refuse it or that they are feeling shy of being tested 5\% ( $8 / 160)$, Table 3 .

The study showed clearly that most of the women who participated in the study preferred the Pap smear test to be taken in hospital 73.5\% (250/340) in gynecological clinic or women's health clinic rather than in private clinic, and $41.7 \%(142 / 340)$ preferred to be taken by a gynecologist.

It is obvious that women working in the medical profession are more aware of cervical cancer and more willing to participate in a screening program if made available, as illustrated in Table 4.

\section{Discussion}

Despite the fact that cervical cancer is the second most common cancer in Sudan and that almost $85 \%$ of patients are diagnosed in advanced stage, there is no established screening programme, Hamad (2006). The screening rate was less that $0.10 \%$ in the last 5 years. This was mainly due to poor or non-existence of infrastructures resulting in failure to sustain screening services. Unfortunately in 2011 more than 990 were diagnosed with cervical cancer and 600 patients died according to registries of the main oncology center in Sudan.

The rate of Pap smear taking was observed to be varying in the different developed and developing countries and this has significantly affected the reported prevalence of cancer in different countries. Different rates of Pap smear testing was reported in various studies; e.g.
$20 \%$ in Kenya (Gichangi et al., 2003), $40.3 \%$ in Jordan (Barghouti et al., 2008) , 69\% in Spain (Byrd et al., 2004), and $93 \%$ in the United States of America (Sirovich et al., 2004) , 28.9\% in Turkey (Gurel et al., 2009). In our study we have shown that 79 of 500 women (15.8\%) included in the study had taken Pap Smear Test before, while 421 women $(84.2 \%)$ had never taken the test before. This rate is representing relatively educated women and resident almost in urban area; Khartoum state. The rate of taking the Pap Smear Test among women is likely to be influenced by their socio-demographic characteristics. For example, Ak et al showed the rate to be low among women with low education level and who lived in rural areas (Ak et al., 2010). The average age was higher among women who took Pap smear test, and these women had more gynecological examinations, lived in the city centre, had higher socio-economic level as well as higher level of knowledge about pap smear test and higher education level. In our study, the rate of taking Pap smear test was observed to be higher among women who were from the age group more than 30 years, who were university graduates, and who were had gynecological examination. Importantly we found a statistically significant relationship between status of taking pap smear test and women's education level, occupation status, residence ( $\mathrm{p}$ value below 0.05).

Similarly, the American College of Obstetricians and Gynaecologist (ACOG) announced that all women who have been sexually active in any period of their lives or are still sexually active, or who have reached the age of 21 should have annual pelvic examination and take Pap Smear Test, and women who are older than 30 years of age and who have normal pelvic examination and Pap smear results for 3 successive years may be monitored up at longer intervals (Byrd et al, 2004; Ozan, 2005).

The percentage of women who had relatively a good knowledge about cervical cancer and Pap smear test as a screening test is $87.8 \%$ and $51.6 \%$ respectively; is higher in educated group of women. Therefore, education is associated with higher awareness about pap smear. Similar results were found by Arevian who report that education is the most important predictor of knowledge about pap smear test even once in their life (Arevian et al., 1997). 
In this survey the majority of women $(75.4 \%)$ were interested to be enrolled in the screening program of cervical cancer. As shown; women preferred that the Pap smear to be taken by the Gynecologist in hospital; obviously this will unnecessary increase load in the hospitals. Whereas only $0.9 \%$ of women who participated in the study would prefer the screening of cervical cancer to be performed by a primary care physician

The major source of information about pap smear test have been delivered through the media and gynecological doctor which indicate that the primary care physician has no role in providing the information about cervical cancer and its detection by the pap smear screening. This may be attributed to a lack of the screening programme in Sudan. Educational programs are required to train primary care physicians about the technique of taking a sample to avoid any sampling error and comprehensive educational programmers about cervical cancer and Papanicolaou test screening should be implemented through the mass media and primary health doctors. Accordingly, it may be concluded that women change their behavior according to their source of information, and are more likely to reflect the information obtained from health institutions to their lives. In a study conducted in Kenya (Gichangi et al., 2003), $87 \%$ of the participants heard about the test from a health institution, $7 \%$ from a friend and 3\% from the media; and in other studies the rate of hearing about the test from a health institution was reported as 57\% and $82 \%$ (Arevian et al., 1997; Kalyoncu et al., 2003).

A number of studies have attempted to determine what factors are associated with not participating in the screening for cervical cancer. One study about pap smear screening among urban South Western American Indian women showed that the limited access to health care and lack of knowledge about the procedure were important barriers to pap smear use (Risendal et al., 1999). Another study, done among Korean-American women, showed that the most frequently cited reason for not having had a Pap smear test was absence of disease symptoms (Kim et al., 1999). Our study showed that the most frequently reported reason for not having a recent pap smear did not believe it was necessary. One of the objectives of this study was to explore why some women do not have a pap test. Given the least proportion (32\%) of women in this study who reported they were refusing to have a pap test, there is clearly a need for such knowledge. The anticipated women who believe that once healthy, there is no need for the test, and that the test might be painful, were two major barriers identified in his study, which represents $36.3 \%, 24.4 \%$ respectively. Feeling shy may be due to cultural influence and presumably has its basis in the women's experiences and in some other general attitudes. Clinicians need to acknowledge this as an important factor for some women, and make efforts to help overcome this when discussing cervical screening and taking the test. For some women, however it may be that familiarity with their clinician is a cause for embarrassment and fear of being diagnosed with a disease. To encourage cervical screening among this group it may be necessary to set up services where confidentiality is assured. In conclusions, consequently, it was determined that women's decisions and awareness about taking Pap Smear Test was affected by their opinions of gynecological examination, sociodemographic characteristics, knowledge about Pap smear test, and risk perceptions about cervix cancer; yet, despite all these factors, the significance of Pap Smear test was not fully acknowledged among women.

Women in general throughout their lives have more frequent contact with health care services particularly at the level of primary care. The high prevalence, long mean duration of a symptomatic detectable disease, and availability of a high specific screening test make cervical cancer screening an important task for all primary care providers.

In line with the obtained findings, it may be suggested that Pap smear test, as in all developed countries, should be performed as part of the annual pelvic examination 3 years after the first sexual experience in our country, as well. Furthermore, health personnel should provide all women with more extensive knowledge about Pap smear and cervix cancer, risk factors, early diagnosis and screening; and if necessary, women should be encouraged to participate in education programs. Also, women who are admitted for gynecological examination should be informed by the health personnel about the objective and significance of Pap Smear test and how often it should be performed; and health education programs on this subject should become widespread and screening programs should appear more often in the media, for example by inserting these slots into the commercial breaks of prime time news programs and TV series and an effective screening program should be developed. These activities will be highly effective in providing women with awareness about cervix cancer and encouraging them to take regular Pap Smear Tests.

Conclusion: Despite the high educational level, less than half of participants were having accurate knowledge about cervical cancer, HPV, and cervical cancer screening program, and the majority had not taken the test before. Long term education should be started to provide the needed information, then impose positive external values, motivate the women population and facilitate taking Pap smear through the primary health care centers in all Sudan because these clinics have the ability to spread the positive knowledge, attitude and practice. A clear policy is required to educate primary care physicians how to perform optimal screening.

\section{References}

Ak M, Canbal M, Turan S, et al (2010). Aile hekimligi poliklinigine basvuran kadınlarda papsmear testinin farkındalıklarının degerlendirilmesi. Konuralp Tip Dergisi, 2, 1-4

Al Zaabi M,Al Muqbali S, Al Sayadi T, et al (2015). Age specific cytological abnormalities in women screened for cervical cancer in the Emirate of Abu Dhabi. Asian Pac J Cancer Prev, 16, 6375-9

Arevian M, Noureddine S, Kabakian T, et al (1997). A survey of knowledge, attitude, and practice of cervical screening. Among Lebanese / American women. Nurs Outlook, 45, 16-22.

Barghouti FF, Takruri AH, Froelicher ES.(2008) Awareness 
and behavior about Pap smear testing in family medicine practice. Saudi Med J. 29, 1036-40.

Byrd T, Peterson S., Chavez R, et al (2004). Cervical cancer screening beliefs among young hispanic women. Prev Med, 38, 192-97.

Elamin A, Ibrahim ME , Abuidris D,et al (2015). Part I: cancer in Sudan - burden, distribution, and trends breast, gynecological, and prostate cancers. Cancer Med, 4, 447-56

Gichangi P, Estambale B, Bwayo J, et al (2003). Knowledge and practice about cervical cancer and Pap smear testing amongpatients at Kenyatta National Hospital, Nairobi, Kenya. IntJ Gynecol Cancer, 13, 827-33.

Gurel AS, Gurel H, Topcuoglu A (2009). Investigation of rate and determinants of pap-test in women attending for a gynecological examination. Turkiye Klinikleri J Gynecol Obst, 19, 62-6

Hamad HM (2006). Cancer initiatives in Sudan, Ann Oncol. 17, 32-36

Kalyoncu C, Iıklı B, Ozalp S, et al (2003). Osmangazi universitesi kadın hastalıklarıve doum polikliniine bavuruların pap smear hakkında bilgi tutumve davranıları. Salıkve Toplum, 13, 60-6

Khan MJ, Partridge EE, Wang SS, et al (2005). vSocioeconomic status and the risk of cervical intraepithelial neoplasia grade 3 among oncogenic human papillomavirus DNA-positive women with equivocal or mildly abnormal cytology. Cancer, 104, 61-70.

Kidanto HL, Kilewo CD, Moshiro C (2002). Cancer of the cervix: knowledge and attitudes of female patients admitted at Muhimbili National Hospital, Dar es Salaam. East Afr Med J, 79, 467-75.

Kim K, Yu ES, Chen EH, et al (1999). Cervical cancer screening knowledge and practices among Korean-American women, Cancer Nurs, 22, 297-302.

Maaita M, Barakat M (2002). Jordanian women's attitudes towardscervical screening and cervical cancer. $J$ Obstet Gynaecol, 22, 421-2.

Ozan H (2005). PAP Smear: When? How? Who? Turkey J Gynecol Obstetrics, 2, 35-40.

Risendal B, DeZapien J, Fowler B, Papenfuss M, Giuliano A (1999). Pap smear screening among urban Southwestern American Indian women. Prev Med, 29, 510-8.

Saslow D, Runowicz CD, Solomon D, et al (2002). American Cancer Society guideline for the early detection of cervical neoplasia and cancer. CA Cancer J Clin, 52, 342-62.

Sirovich BE, Welch HG (2004). The frequency of Pap smear screening in the United States.J Gen Intern Med, 19, 243-50

Wellensiek N, Moodley M, Moodley J, et al (2002). Knowledge of cervical cancer screening and useof cervicalscreening facilities among women from varioussocioeconomic backgrounds in Durban, Kwazulu Natal, South Africa. Int J Gynecol Cancer; 12, 376-82.

World Health Organization. Cervical cancer, human papillomavirus (HPV) and HPV vaccines: Key points for policy-makers and health professionals. WHO Press, 2008. World Health Organization, 20 Avenue Appia, 1211 Geneva 27, Switzerland.

World Health Organization (1986). Control of cancer of thecervix uteri: review article based on a report of a WHOmeeting, November 1985, Geneva. Bull World HealthOrgan, 64, 607-18. 